\title{
Climate and Environmental Benefit Study of PV Resource Development: Case Study of Angola
}

\author{
Yu LEI ${ }^{\mathrm{a}, 1}, \mathrm{Xi} \mathrm{LU}^{\mathrm{b}}$, Ying WANG ${ }^{\mathrm{a}}$, Haoqiang GUO ${ }^{\mathrm{a}}, \mathrm{Yu} \mathrm{WANG}^{\mathrm{a}}$ and Zhuojun \\ $\mathrm{ZHONG}^{\mathrm{a}}$ \\ a Dongfang Electric Engineering \& Consulting Co., Ltd., Chengdu 611731, Sichuan, \\ China \\ ${ }^{\mathrm{b}}$ School of Environment and State Key Joint Laboratory of Environment Simulation \\ and Pollution Control, Tsinghua University, Beijing 10084, China
}

\begin{abstract}
Vigorously promoting the development of photovoltaic (PV) resources is a positive measure taken by humanity in response to the changes in global climate and environment. At the same time, combining photovoltaic power generation systems with traditional power generation systems, using the advantages of different power generation systems to achieve real-time scheduling optimization has become an urgent problem to be solved in engineering applications. This paper attempts to study the climate and environmental benefits of the development of photovoltaic resource in Africa by taking Angola as an example based on actual project data. According to the characteristics, load requirements, seasonal characteristics and actual engineering background of Tombwa in Angola, a baseline Scenario and four comparative Scenarios were established, and the operating costs of the five Scenarios in local rainy season and dry season were obtained respectively. The cost of electricity for the five Scenarios calculated subsequently. Through real-time scheduling and optimization of the software, the emission characteristics of $\mathrm{CO}_{2}, \mathrm{NO}_{\mathrm{x}}$ and $\mathrm{CO}$ under five Scenarios are obtained, and the climate benefits and environmental benefits of the five scenarios are further analyzed and compared. The results show that the development of photovoltaic resources in Angola has good climate and environmental benefits. In addition, the combine application of diesel, PV and battery power system will be the most effective of the five Scenarios to reduce the $\mathrm{CO}^{2}$ emissions with the lowest levelized cost of electricity (LCOE) of 0.38 yuan/kwh, as a cost-effective solution in remote areas of Angola, Africa.
\end{abstract}

Keywords. Photovoltaic resource, power generation system, environmental benefits

\section{Introduction}

As the second largest continent with population of about 1.3 billion, Africa has become a new economic engine in the world, with vast potential for growth in the near future [1]. Nowadays, Africa is facing a serious shortage of power [2], and the construction of power infrastructure has become the primary task of Africa's development. As the

${ }^{1}$ Corresponding Author, Yu LEI, Dongfang Electric Engineering \& Consulting Co., Ltd., Chengdu 611731, Sichuan, China; Email: leiyu@dongfang.com.cn. 
disparity between the power supply and demand of conventional energy is increasingly aggravating and the climatic and environmental issues are increasingly prominent, most African countries start to seek new power energy alternatives from the perspective of sustainable development and energy security [3].

Half of the total solar radiation on the Earth comes from Africa. $80 \%$ of the land surface radiation in Africa can reach $2000 \mathrm{kWh} / \mathrm{m}^{2}$ per year [4]. The solar energy resources in the Sahara Desert and the East African Plateau are particularly abundant. The annual radiation in this area can reach more than $2500 \mathrm{kWh} / \mathrm{m}^{2}$. Abundant solar energy resources can provide new options for power supply in Africa. Being one of the African countries, Angola's development is also constrained by weak power infrastructure and severe shortages of power production and supply. According to BMI's Angola Power Report in the fourth quarter of 2016, Angola's access ratio in 2016 was only $37 \%$, and its power supply quality ranked only 138 in the world. In Angola's vast countryside, the access ratio is only $10 \%$. It is too costly to install large grid connected power lines over vast distances to supply electricity to a small number of people [5]. In order to meet the demand of rural power load, the local government began to seek to develop the Hybrid Power System (HPS) project to cope with the current situation. HPS system includes solar photovoltaic power generation, small wind turbines, diesel engines, micro gas turbines and energy storage system to meet the needs of electricity in special circumstances with either the grid-connected or isolated operation mode. Distributed energy project based on solar photovoltaic power generation is of great practical significance in isolated grid towns, islands and remote settlements. Because of the attributes of natural gas, coal and diesel resources, power plants with these fuels appear to have the emission problems and power generation costs in pairs of contradictions. Energy costs and emission are always accompanied by HPS power generation system. The real-time scheduling optimization of power generation system with emission and operation cost has become the focus of energy saving and emission reduction research.

Several excellent reviews describing these applications are available, Dekker et al. [6], have done some quantitative research on the analysis of photovoltaic resources in different regions of South Africa and the structure optimization and power matching of Diesel and PV with the help of HOMER software under fixed oil price, this paper considered the net present value (NPV), carbon dioxide emissions and the proportion of photovoltaic capacity during the operation period of the project. However, the quantitative analysis of the cost of HOMER software is based on preset values, and the safety mode of software black box is not suitable for the expansion of later functions and personalized research needs [7], there are differences in fuel consumption rate and emission rate of climatic environmental impacts under different operating conditions for diesel generating units. Low load "off-design operation" of diesel generating units in HPS is one of the key points of dispatching optimization research. Mohammed et al. [7] establish a model to optimize the capacity allocation and scheduling operation of HPS in a certain time range. The dynamic real-time models of photovoltaic, diesel and energy storage battery are proposed. The control strategies of load tracking and cyclic charging are applied in the research, especially the complex dynamic real-time battery charging and discharging model. Maammeur et al. [8] took a large farm in Northwest Algeria as an example to meet farm demand by combining photovoltaic power generation system with local power grid. David et al. [9] modeled and optimized the system using only diesel engine and photovoltaic power generation under isolated grid conditions, taking full account of local irradiation intensity and load demand, in order 
to find the lowest calculation results of power cost. The results show that, under the same external conditions, the diesel engine and photovoltaic complementary power system is superior to the single diesel engine power generation operation system in the calculation of electricity cost. Nfah et al. [10] took the smaller micro-grid in northern Cameroon as the research object, established three Scenarios of diesel and photovoltaic HPS, pure photovoltaic power generation system and stand-alone diesel engine power generation system for economic analysis. The sensitivity analysis of diesel price and photovoltaic module price was also carried out in this paper. The research shows that the Diesel-PV complementary power generation system is helpful to popularize in remote rural areas, and it is an effective way to improve rural access power efficiency in Cameroon. Focusing on efficiency and emissions in the field of power in Africa, but there are few case studies of photovoltaic and diesel generator complementary systems without energy storage cells in Africa, and there are few studies on the use of gas turbines or diesel engines as conventional power generation and photovoltaic complementarity to meet load demand. Many articles about the analysis and research of carbon dioxide emissions, but not on the environmental benefits of photovoltaic resources utilization in other environmental pollutants.

\section{Material and Methods}

We analyze the acquired site data of Tombwa (latitude $-15.77^{\circ} \mathrm{S}$, longitude $11.92^{\circ} \mathrm{E}$ ), located in the province of Namibe, southwest of Angola, Africa. Average daily load and annual load duration curves were constructed to see the pattern of demand for electricity in Tombwa by analyzing electricity loads in buildings or site locations for which data were available. More data about the site please refer to the Support Information.

In this study solar PV system and diesel or gas turbine generator are combined together to harness the clean solar power and at the same time to compensate for the unpredictable fluctuation in sunlight and to cater to the load after sundown. Battery is utilized to ensure uninterrupted power and maintain the desired power quality at the load terminals. Moreover, continuous use of diesel or gas turbine is not envisaged as it is costly and noisy with harmful emissions. Using of the two sources in parallel with battery storage thus provides a smooth, distributed output. This in turn will make the power system more reliable, efficient and less maintenance.

In order to realize the integrity and contrast significance of the research content baseline Scenario, five kinds of targeted research Scenarios in table 1 are derived, which form the basis of the research object model.

Table 1. Description of the 5 scenarios.

\begin{tabular}{lllll}
\hline No & Item & PV & Diesel/gas turbine & Storage battery \\
\hline Scenario 1 & SAD & $0 \mathrm{MWp}$ & $4 \times 5000 \mathrm{~kW}$ & 0 \\
Scenario 2 & D + PV & $12 \mathrm{MWp}$ & $3 \times 5000 \mathrm{~kW}$ & 0 \\
Scenario 3 & GT + PV & $12 \mathrm{MWp}$ & $3 \times 5000 \mathrm{~kW}$ & 0 \\
Scenario 4 & D + PV+B & $12 \mathrm{MWp}$ & $2 \times 5000 \mathrm{~kW}$ & $5 \mathrm{MWh}$ \\
Scenario 5 & GT + PV $+\mathrm{B}$ & $12 \mathrm{MWp}$ & $2 \times 5000 \mathrm{~kW}$ & $5 \mathrm{MWh}$ \\
\hline
\end{tabular}

Scenario 1 is the base Scenario in this research. To make it more comprehensive, the control strategy of Scenario 2, 3, 4 and 5 based on the variation of load and power 
output of photovoltaic system and diesel engine of different operation conditions will be analyzed, furthermore, the fuel consumption rate of low load operation conditions [11] will be considered. To simplify the case, some of simulation assumes adopted by this paper.

\section{Theory and Calculation}

(1) Objective function of minimum operating cost

$$
\min \mathrm{C}=\sum_{i=1}^{n} a_{i} P_{i, t}^{2}+b_{i} P_{i, t}+\sum_{t=1}^{T} \sum_{i=1}^{N} C_{s t c} y_{i, t}+\sum_{t=1}^{T} \sum_{i=1}^{N} C_{s t d} Z_{i, t}
$$

where subscripts $\mathrm{i}$ and $\mathrm{t}$ represent the generator number and the scheduling cycle respectively, $a_{i}, b_{i}$, refer to fuel consumption coefficient in catchment $i, C_{\text {stc }}$ and $C_{\text {std }}$ indicate fixed cost of powering up and shutting down once time respectively, $\mathrm{y}_{\mathrm{i}, \mathrm{t}}$ and $\mathrm{z}_{\mathrm{i}, \mathrm{t}}$ indicate state variables.

(2) Constraint condition [12]

System output constraint:

$$
\sum_{i=1}^{N} P_{i, t}+p v_{t}+p d_{t}=\text { demand }_{t}+p c_{t}
$$

where, $\mathrm{P}_{\mathrm{i}, \mathrm{t}}$ is the output of generator $\mathrm{i}$ at time t. $\mathrm{pv}_{\mathrm{t}}$ is the output of $\mathrm{PV}$ at time $\mathrm{t}, \mathrm{pd}_{\mathrm{t}}$ is the discharge of Storage Battery, demand $t_{t}$ is the load demand at time $t, \mathrm{pc}_{t}$ is the charging capacity of the Storage Battery.

(3) PV modeling constraint

$$
\begin{gathered}
p v_{t}+p v c_{t}=c a p_{t} \\
0 \leq \sum_{t=1}^{T} p v c_{t} / \sum_{t=1}^{T} c a p_{t} \leq R_{c u t}
\end{gathered}
$$

where $\mathrm{pvc}_{\mathrm{t}}$ refer to the curtailment of $\mathrm{PV}, \mathrm{cap}_{\mathrm{t}}$ is the predict output at time $\mathrm{t}, \mathrm{R}_{\mathrm{cut}}$ indicate the curtailment of PV.

(4) Storage Battery modeling constraint

$$
\operatorname{soc}_{t}=\operatorname{soc}_{t-1}+p c_{t} \cdot c-p d_{t} \cdot d
$$

where $\mathrm{SOC}_{\mathrm{t}}$ is the battery state of charge at time $\mathrm{t}, \mathrm{pc}_{\mathrm{t}}$ is the charging capacity, $\mathrm{c}$ is the charging efficiency, $\mathrm{pd}_{\mathrm{t}}$ is the discharging capacity, $\mathrm{d}$ is the discharge rate of the Storage Battery.

(5) Output fluctuation constraint

$$
\sum_{i=1}^{N}\left(P_{i}^{\max }-P_{i, t}\right) \geq \operatorname{demand}_{t} R_{d}+p v_{t} R_{P V}
$$


where the $P_{i}{ }^{\max }$ refer to the generator output up-limit, $R_{d}$ indicate the probability of load fluctuation, $\mathrm{R}_{\mathrm{pv}}$ is $\mathrm{PV}$ output fluctuate rate.

\section{Results}

\subsection{Scenarios Modelling Optimal}

Figure 1 shows the operation for reaction on the real-time scheduling optimization under the constraint condition. SAD scenario, when the load demand become high in rainy season, at 8:00 to 23:00, there are 3 unites servicing under the modelling optimal (actually, for the longtime heavy maintenance of the diesel, we have to consider a spare unit). While for the D+PV Scenario, consider the PV system attribute and the cost of this scenario, no additional diesel unit hence. Figure 1 with D+PV scenario, two diesel units operate from 6:00 to 16:00. Constraint condition preset makes the diesel work at a steady state with the power range $2.9 \sim 3.7 \mathrm{MW}$, that means high engine efficiency in this range and low operation costs of the units. We can find out the difference between $\mathrm{D}+\mathrm{PV}$ and $\mathrm{D}+\mathrm{PV}+\mathrm{B}$ Scenario, from 16:00 to 23:00, for the usage of the storage battery, even in the high load demand of rainy season, only two units of diesel put into operate in $\mathrm{D}+\mathrm{PV}+\mathrm{B}$ scenario, with the same condition of meeting the requirement. The same analysis results can come out with GT $+\mathrm{PV}$ and GT $+\mathrm{PV}+\mathrm{B}$ scenario.

We can find that the power system with Storage Battery have a subtle effect on curtailment of PV with the low load requirement in dry season. The PV system will supply power to meet the load demand while any excess power from the PV will be stored in the battery until maximum capacity of battery is reached. The dash area of figure 2, from the time 12:00 to 15:00, is the curtailment of PV in D+PV scenarios, with the instantaneous maximum power $1.2 \mathrm{MW}$. This situation can be avoided in $\mathrm{D}+\mathrm{PV}+\mathrm{B}$ Scenario, figure 2 . In this study solar PV system and diesel or gas turbine generator are combined together to harness the clean solar power modelling optimal $\mathrm{D}+\mathrm{PV}+\mathrm{B}$ Scenario.

Figure 3 show us another result we may care by the modelling optimal output of $\mathrm{D}+\mathrm{PV}+\mathrm{B}$ from time $20: 10$ to the midnight, the capacity of the Battery was reduced from $2 \mathrm{MWh}$ to rock bottom $0.5 \mathrm{MWh}$, that is to say, the depth of the battery discharging in a single cycle, is far more than the $50 \%$ of the total capacity of the battery.

\subsection{Economic Benefit Calculation}

Summing up the 5 scenarios by LCOE, take GT+PV+B initial investment for example, PV power system $42.92 \%$, following is gas turbine $30.03 \%$, Storage Battery $14.35 \%$, construction and installation on site is $9.65 \%$, detailed in Support Information. We can see the result in table 2, The real-time scheduling optimization demonstrated that the lowest LCOE was D+PV+B, 0.38RMB/kWh.

Summing up the 5 scenarios by LCOE, take GT $+\mathrm{PV}+\mathrm{B}$ initial investment for example, PV power system $42.92 \%$, following is gas turbine $30.03 \%$, Storage Battery $14.35 \%$, construction and installation on site is $9.65 \%$, detailed in Support Information. We can see the result in table 2, The real-time scheduling optimization demonstrated that the lowest LCOE was D+PV+B, $0.38 \mathrm{RMB} / \mathrm{kWh}$. 

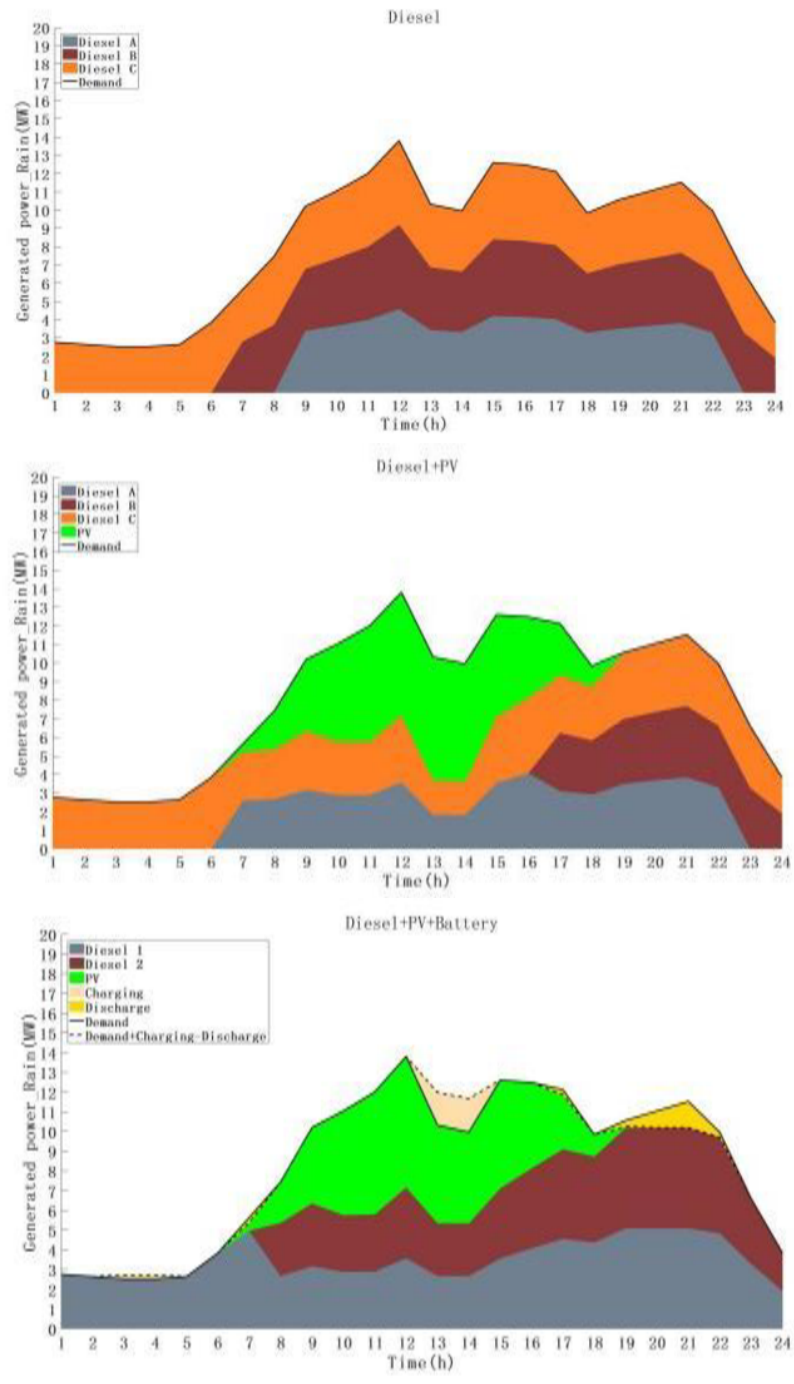

Figure 1. Real-time scheduling optimization in rainy season.
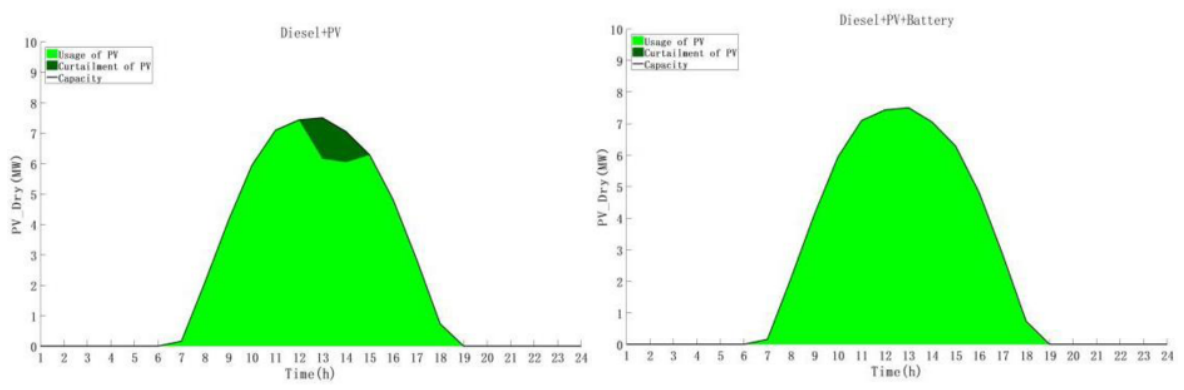

Figure 2. Curtailment of PV in Diesel + PV. 


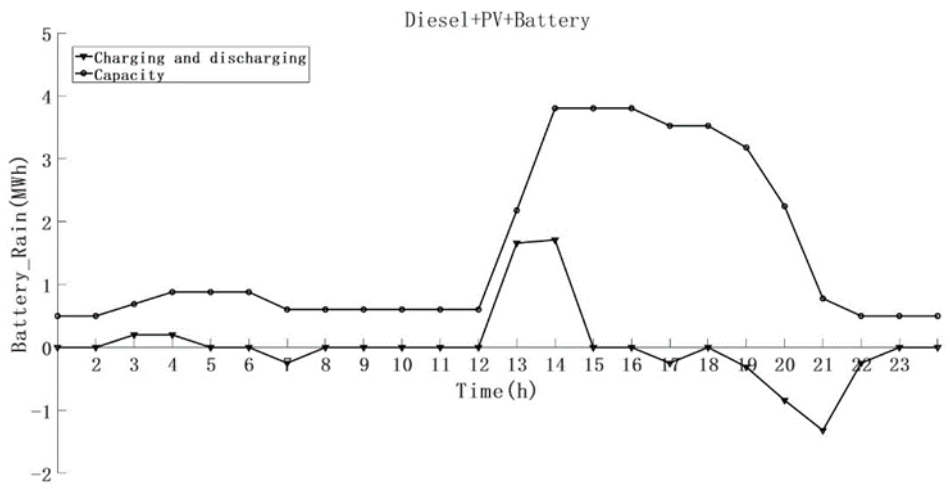

Figure 3. Storage battery in $\mathrm{D}+\mathrm{PV}+\mathrm{B}$ rainy season.

Table 2. Scenario economic results.

\begin{tabular}{|c|c|c|c|c|c|}
\hline Scenario & Season & Operating Costs (RMB/day) & LCOE (RMB/kWh) & Fuel consumption (kg/day) & Fuel \\
\hline \multirow{2}{*}{ SAD } & Rainy & 175335 & \multirow{2}{*}{0.48} & 40307 & Diesel \\
\hline & Dry & 131928 & & 30328 & Diesel \\
\hline \multirow{2}{*}{$\mathrm{D}+\mathrm{PV}$} & Rainy & 130877 & \multirow{2}{*}{0.41} & 30086 & Diesel \\
\hline & Dry & 85375 & & 19626 & Diesel \\
\hline \multirow{2}{*}{$\mathrm{GT}+\mathrm{PV}$} & Rainy & 173384 & \multirow{2}{*}{0.49} & 40796 & Gas \\
\hline & Dry & 114790 & & 27009 & Gas \\
\hline \multirow{2}{*}{$\mathrm{D}+\mathrm{PV}+\mathrm{B}$} & Rainy & 130342 & \multirow{2}{*}{0.38} & 29963 & Diesel \\
\hline & Dry & 83571 & & 19211 & Diesel \\
\hline \multirow{2}{*}{$\mathrm{GT}+\mathrm{PV}+\mathrm{B}$} & Rainy & 159897 & \multirow{2}{*}{0.45} & 37622 & Gas \\
\hline & Dry & 110339 & & 25962 & Gas \\
\hline
\end{tabular}

For the LCOE of the SAD, D+PV, D+PV+B scenario, LCOE is 0.48, 0.41, 0.38, separately by using of PV and Battery.

We contrast the operating cost of the $\mathrm{D}+\mathrm{PV}$ and GT $+\mathrm{PV}$ scenario in table 2, for rainy season, the operating cost of the GT+PV is $173384 \mathrm{RMB} /$ day, which is higher than the D+PV 130877RMB/day. Reason for this difference is the high efficiency of the diesel generator which lead to the fuel consumption lower than that of the gas turbine, for the price of one-unit gas and diesel oil are nearly equivalent under the same net calorific value.

\section{3. $\mathrm{CO}_{2}, \mathrm{NO}_{x}, \mathrm{CO}$ Emissions and Fuel Consumption}

Taking the $\mathrm{SAD}$ and $\mathrm{D}+\mathrm{PV}$ scenario for indication, we find that, $\mathrm{SAD} \mathrm{CO}_{2}$ emission from 6:00 to 18:00 with the peak point at 12:00, 9.3t/h, figure 4a. The D+PV scenario get the peak $\mathrm{CO}_{2}$ emission only $4.8 \mathrm{t} / \mathrm{h}$, figure $4 \mathrm{~b}$, at $12: 00$, by the effect of the PV.

\section{Discussion}

This paper takes the lowest operation cost for the 5 scenarios as the objective function, calculating the LCOE and analysis the environment benefits with the operating and emission data came out of the scheduling modeling optimal. The research shows that 
(1) Comparing to the Scenario SAD, under the conditions of meeting the same local load demand curve, $\mathrm{D}+\mathrm{PV}+\mathrm{B}$ prevents a total sum of $\mathrm{CO}_{2} 326,500$ tons, $\mathrm{NO}_{\mathrm{x}}$ $2,030.7$ tons, CO 208.8 tons, reduced the consumption of diesel fuel by 97,150 tons, ceteris paribus, in the operating life of 25 years. The system has an evident contribute to the climate and environment.

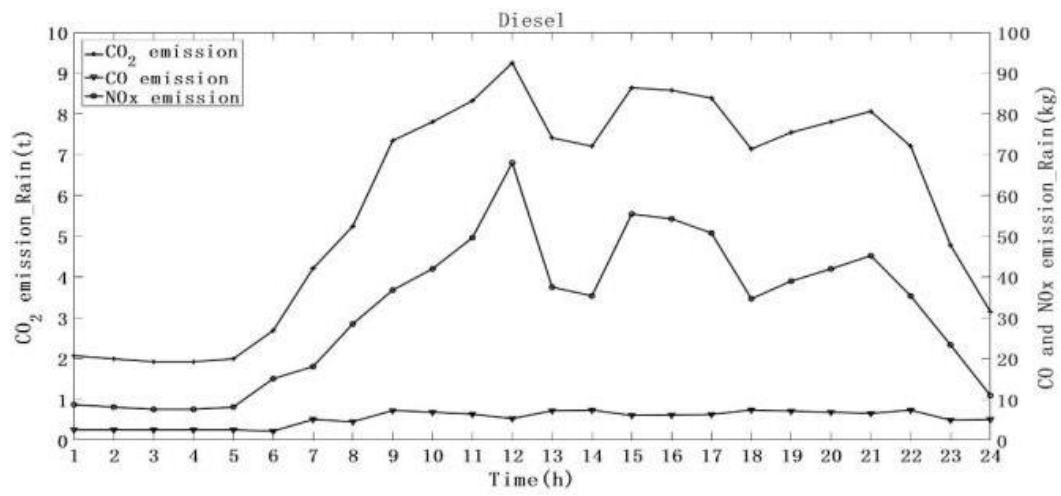

(a) SAD scenario

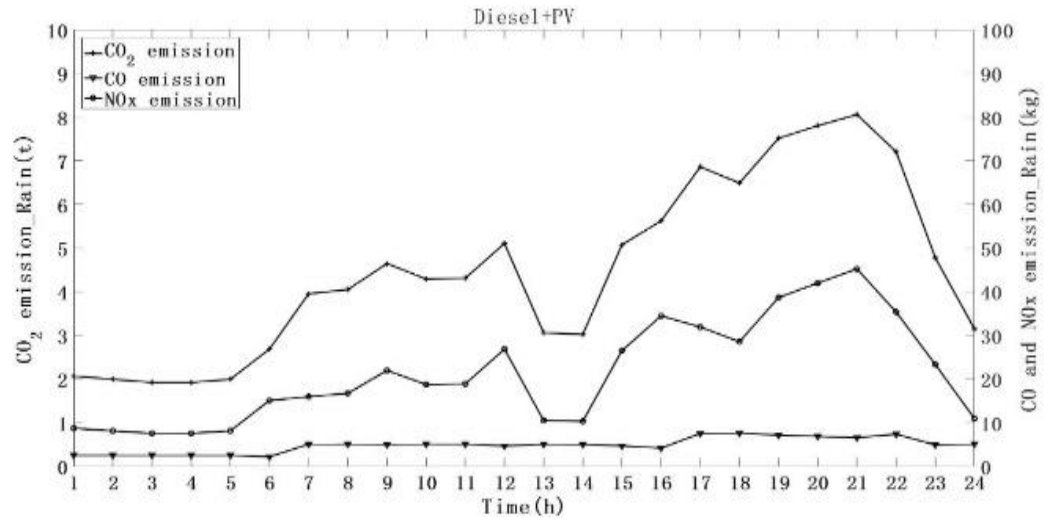

(b) D+PV scenario

Figure 4. Emission diagram after model optimization.

(2) By adopting the real-time scheduling optimization, we can reduce the consumption of the chemical fuel and the following climate and environment influencer emission, under the condition of meeting of the load requirement. The uneconomic operation of the standalone diesel at the low load demand situation can be resolved by the using of $\mathrm{PV}$ or Battery system. The $\mathrm{D}+\mathrm{PV}+\mathrm{B}$ power system make a balance between the high initial investment but good benefits of climate and environment and the high operating cost but harmful to the climate and environment. The lowest $\mathrm{LCOE}$ of $\mathrm{D}+\mathrm{PV}+\mathrm{B} 0.38 \mathrm{RMB} / \mathrm{kWh}$ indicates that it is capable for commercial promotion.

(3) This paper can give a reference for the controversy nowadays that which is better for adopting the diesel oil engine or micro-gas-turbine generator in the HPS and other distributed energy sources system. In Africa, different country has different 
energy resource endowment. The Egypt, south Africa, Mozambique are rich in coal fuel, while Nigeria, Angola are rich in oil and gas. Angola ranks second in Africa in oil production, this makes the diesel oil engine and PV power system can be promoted, especially in the grand remote area of the country. In fact, some of the project located in the countries with abundant gas, the diesel engine, more accurately called internal combustion engine, operating with gas fuel, take up both good environment benefits and high engine efficiency. The dispute may stop immediately.

(4) It is a negative effect on the life of the battery for the discharging below 0.5 SOC in a single loop, especially not good for the project with battery in the remote area of Africa, for the difficult transportation of the new heavy battery. We can improve this power system in remote area with off-gird power system, by setting the constraint discharging condition of the battery reasonably at the beginning of the scheduling modeling optimal.

\section{Conclusions}

This paper focus on the real-time scheduling optimization under the given initial configuration of the power system capacity, which PV, Diesel, Gas turbine, Storage Battery are combined with the actual engineering parameters. Under the condition of given demand load, the power system capacity parameters solved by iterative method are worth studying in the next stage. In this way, the optimization scheduling method proposed in this paper can complete the research from system capacity allocation selection to LCOE and climate and environmental benefits.

Delivering power to arid regions is still a serious problem for both public and private organizations. The small number of inhabitants and the distance from fossil resources and grid electricity make electricity supply easier said than done. This study is realized for city of Tombwa, Angola, which can be easily adopted for other cities. The promotion and application of HPS power stations in Africa can not only help solve the problem of scattered settlements of people in Africa, but also provide a rational choice for Africa to cope with its current situation and global climate change, paving for low-carbon development in Africa.

\section{References}

[1] Kohnert D 2021 On the socio-economic impact of pandemics in africa: lessons learned from covid-19, trypanosomiasis, HIV, yellow fever and cholera MPRA Paper.

[2] Heffner G, Maurer L, Sarkar A, et al. 2010 Minding the gap: World bank's assistance to power shortage mitigation in the developing world Energy 35 (4) 1584-1591.

[3] Ackah I and Kizys R 2015 Green growth in oil producing African countries: A panel data analysis of renewable energy demand Renewable and Sustainable Energy Reviews 50 (2015) 1157-1166.

[4] Fant C, Schlosser C A and Strzepek K 2016 The impact of climate change on wind and solar resources in Southern Africa Wider Working Paper 161 (Jan.1) 556-564.

[5] Hansjörg and Gabler 1998 Autonomous power supply with photovoltaics: photovoltaics for rural electrification - reality and vision Renewable Energy.

[6] Dekker J, Nthontho M, Chowdhury S, et al. 2012 Economic analysis of PV/diesel hybrid power systems in different climatic zones of South Africa International Journal of Electrical Power \& Energy Systems 40 (1) 104-112.

[7] Ameen A M, Pasupuleti J and Khatib T 2015 Simplified performance models of photovoltaic/diesel generator/battery system considering typical control strategies Energy Conversion and Management 99 313-325. 
[8] Maammeur H, Hamidat A, Loukarfi L, et al. 2017 Performance investigation of grid-connected PV systems for family farms: Case study of North-West of Algeria Renewable and Sustainable Energy Reviews 78 1208-1220.

[9] Tsuanyo D, Azoumah Y, Aussel D and Neveu P 2015 Modeling and optimization of batteryless hybrid PV (photovoltaic)/diesel systems for off-grid applications Energy 86 (Jun.15) 152-163.

[10] Mbaka N E, Mucho N J and Godpromesse K 2010 Economic evaluation of small-scale photovoltaic hybrid systems for mini-grid applications in far north Cameroon Renewable Energy 35 (10) 2391-2398.

[11] Yilmaz S and Dincer F 2017 Optimal design of hybrid PV-diesel-battery systems for isolated lands: A case study for Kilis, Turkey Renewable and Sustainable Energy Reviews 77 344-352.

[12] Soroudi A 2017 Power System Optimizaiton Modeling in GAMS (Dublin: Springer International Publishing AG).

[13] System Optimizaiton Modeling in GAMS (Dublin: Springer International Publishing AG). 